\title{
Dysphagia Management in Stroke Rehabilitation
}

\author{
Danielle N. Johnson · Hannah J. Herring • \\ Stephanie K. Daniels
}

Published online: 2 September 2014

(C) Springer Science + Business Media New York 2014

\begin{abstract}
Oropharyngeal dysphagia is a frequent occurrence following stroke. The length of acute care hospitalization, however, has decreased over time with many individuals weak and frail upon admission for rehabilitation and possibly with continued dysphagia upon discharge. It is imperative that the swallowing therapist have a thorough understanding of evidence-based compensatory and exercise management strategies at all stages of recovery for patients with dysphagia following stroke.
\end{abstract}

Keywords Dysphagia $\cdot$ Stroke $\cdot$ Evidence-based practice . Rehabilitation

\section{Introduction}

Oropharyngeal dysphagia following acute stroke is prominent occurring in approximately $50 \%$ of patients [1] with many patients warranting extended management of their swallowing problems. The length of acute care hospitalization for stroke has decreased by $47 \%$ from 1989 to 2009 [2]. A review of Medicare 2012 hospitalizations for stroke revealed the average length of acute care hospitalization ranged from 3.1 days for uncomplicated stroke to 6.8 days for a stroke with major complications or comorbidity [3]. Furthermore, average length of stay (LOS) for

D. N. Johnson · H. J. Herring · S. K. Daniels

Department of Communication Sciences and Disorders, University of Houston, 100 Clinical Research Services, Houston, TX 77204-6018, USA

S. K. Daniels $(\bowtie)$

Research Service Line, Michael E. DeBakey VA Medical Center, 2002 Holcombe Blvd, Houston, TX 77030, USA

e-mail: skdaniels@uh.edu stroke rehabilitation ranged from 7.6 days to 10.0 days depending on stroke complications. Given these findings of shortened hospitalization, it appears obvious that patients entering stroke rehabilitation may be very weak and still requiring compensatory strategies for dysphagia. The time devoted to inpatient rehabilitation is also constrained by shortened LOS. As such, it is critical that the swallowing therapist have a thorough understanding of both compensatory strategies and exercises to address the needs of patients admitted for stroke rehabilitation and the knowledge to devise a management program that progresses as the patient's endurance, cognition, and comprehension improve and transitions to the home or outpatient setting.

\section{Compensation}

Management of dysphagia includes the incorporation of compensatory strategies to immediately address swallowing safety (e.g., aspiration) and efficiency (e.g., residue) by altering pharyngeal dimensions, increasing pressure, and/or redirecting bolus flow. Compensatory strategies provide immediate effects, and as of yet, they have not been identified as providing long-term effects [4]. The clinician must consider the patient's underlying swallowing impairment, e.g., reduced base of tongue (BOT) retraction, in addition to the observed dysphagia sign, e.g., vallecular residue, when determining the optimal compensation (Table 1). Additional considerations when recommending compensatory strategies include the patient's cognitive and comprehension capabilities in addition to any physical limitations. A compensatory strategy such as chin tuck may eliminate aspiration of thin liquids, yet it provides no benefit if the patient cannot remember to use it with each liquid bolus or a caretaker is unavailable at mealtime to 
Table 1 Compensatory and rehabilitative strategies based on sign and underlying technique

\begin{tabular}{|c|c|c|c|c|}
\hline Occurring & Sign & $\begin{array}{l}\text { Secondary to physiologic } \\
\text { abnormality of... }\end{array}$ & Possible compensation strategies & Possible exercise approaches \\
\hline Pre-swallow & $\begin{array}{l}\text { Anterior } \\
\text { leakage }\end{array}$ & $\begin{array}{l}\text { Reduced orolingual } \\
\text { control }\end{array}$ & Thickened liquids & Labial resistance exercises \\
\hline Pre-swallow & $\begin{array}{l}\text { Inadequate } \\
\text { bolus } \\
\text { preparation }\end{array}$ & $\begin{array}{l}\text { Reduced orolingual } \\
\text { control }\end{array}$ & Chopped or pureed solids & Lingual resistance exercises \\
\hline Pre-swallow & $\begin{array}{l}\text { Discoordinated } \\
\text { bolus transfer }\end{array}$ & $\begin{array}{l}\text { Reduced orolingual } \\
\text { control }\end{array}$ & 3-s preparation ${ }^{\mathrm{a}}$ & Lingual resistance exercises \\
\hline $\begin{array}{l}\text { Post- } \\
\text { swallow }\end{array}$ & Oral residue & $\begin{array}{l}\text { Reduced orolingual } \\
\text { control }\end{array}$ & $\begin{array}{l}\text { 1. Dry swallow } \\
\text { 2. Cyclic ingestion } \\
\text { 3. Carbonation }{ }^{\mathrm{a}} \\
\text { 4. Sour bolus }\end{array}$ & Lingual resistance exercises \\
\hline Pre-swallow & $\begin{array}{l}\text { Pharyngeal } \\
\text { pooling }\end{array}$ & $\begin{array}{l}\text { Reduced orolingual } \\
\text { control }\end{array}$ & $\begin{array}{l}\text { 1. 3-s preparation } \\
\text { 2. Chin tuck } \\
\text { 3. Volume regulation } \\
\text { 4. Thickened liquids }\end{array}$ & Lingual resistance exercises \\
\hline Pre-swallow & $\begin{array}{l}\text { Pharyngeal } \\
\text { pooling }\end{array}$ & $\begin{array}{l}\text { Delayed pharyngeal } \\
\text { swallow }\end{array}$ & $\begin{array}{l}\text { 1. 3-s preparation } \\
\text { 2. Chin tuck } \\
\text { 3. Volume regulation } \\
\text { 4. Thickened liquids } \\
\text { 5. Thermal tactile application } \\
\text { b. Sour bolus }\end{array}$ & Thermal tactile application $^{\mathrm{a}}$ \\
\hline $\begin{array}{l}\text { During } \\
\text { swallow }\end{array}$ & $\begin{array}{l}\text { Nasal } \\
\text { regurgitation }\end{array}$ & $\begin{array}{l}\text { Reduced pharyngeal } \\
\text { motility }\end{array}$ & $\begin{array}{l}\text { 1. Volume regulation } \\
\text { 2. Change consistency }\end{array}$ & Masako maneuver \\
\hline $\begin{array}{l}\text { During } \\
\text { swallow }\end{array}$ & $\begin{array}{l}\text { Nasal } \\
\text { regurgitation }\end{array}$ & $\begin{array}{l}\text { Decreased BOT PPW } \\
\text { contact }\end{array}$ & $\begin{array}{l}\text { 1. Volume regulation } \\
\text { 2. Change consistency }\end{array}$ & $\begin{array}{l}\text { 1. Masako maneuver } \\
\text { 2. Mendelsohn maneuver } \\
\text { 3. Gargling }\end{array}$ \\
\hline $\begin{array}{l}\text { During } \\
\text { swallow }\end{array}$ & $\begin{array}{l}\text { Nasal } \\
\text { regurgitation }\end{array}$ & $\begin{array}{l}\text { Decreased UES opening } \\
2^{\circ} \text { reduced anterior HLC } \\
\text { movement }\end{array}$ & $\begin{array}{l}\text { 1. Volume regulation } \\
\text { 2. Change consistency }\end{array}$ & $\begin{array}{l}\text { 1. Mendelsohn maneuver } \\
\text { 2. Shaker exercise } \\
\text { 3. Shaker variations }{ }^{\mathrm{a}}\end{array}$ \\
\hline $\begin{array}{l}\text { During } \\
\text { swallow }\end{array}$ & $\begin{array}{l}\text { Nasal } \\
\text { regurgitation }\end{array}$ & $\begin{array}{l}\text { Intrinsic UES tissue } \\
\text { changes }\end{array}$ & $\begin{array}{l}\text { 1. Volume regulation } \\
\text { 2. Change consistency }\end{array}$ & No available exercises \\
\hline $\begin{array}{l}\text { During } \\
\text { swallow }\end{array}$ & $\begin{array}{l}\text { Reduced } \\
\text { epiglottic } \\
\text { deflection }\end{array}$ & $\begin{array}{l}\text { Decreased HLC } \\
\text { movement }\end{array}$ & $\begin{array}{l}\text { 1. Effortful swallow }{ }^{\mathrm{b}, \mathrm{d}} \\
\text { 2. Mendelsohn maneuver }\end{array}$ & $\begin{array}{l}\text { 1. Expiratory muscle strength training } \\
\text { 2. Effortful swallow }{ }^{\mathrm{d}} \\
\text { 3. Mendelsohn maneuver }\end{array}$ \\
\hline $\begin{array}{l}\text { During } \\
\text { swallow }\end{array}$ & $\begin{array}{l}\text { Reduced } \\
\text { epiglottic } \\
\text { deflection }\end{array}$ & $\begin{array}{l}\text { Intrinsic epiglottic tissue } \\
\text { changes }\end{array}$ & No available strategies & No available exercises \\
\hline $\begin{array}{l}\text { Post- } \\
\text { swallow }\end{array}$ & $\begin{array}{l}\text { Vallecular } \\
\text { residue }\end{array}$ & $\begin{array}{l}\text { Decreased BOT PPW } \\
\text { contact }\end{array}$ & $\begin{array}{l}\text { 1. Dry swallow } \\
\text { 2. Cyclic ingestion } \\
\text { 3. Chin tuck }{ }^{\mathrm{a}} \\
\text { 4. Carbonation } \\
\text { 5. Effortful swallow } \\
\text { 6. Sour bolus }\end{array}$ & $\begin{array}{l}\text { 1. Lingual resistance exercises } \\
\text { 2. Masako maneuver } \\
\text { 3. Effortful swallow }\end{array}$ \\
\hline $\begin{array}{l}\text { Post- } \\
\text { swallow }\end{array}$ & $\begin{array}{l}\text { Vallecular } \\
\text { Residue }\end{array}$ & $\begin{array}{l}\text { Reduced epiglottic } \\
\text { deflection } 2^{\circ} \text { decreased } \\
\text { HLC movement }\end{array}$ & $\begin{array}{l}\text { 1. Dry swallow } \\
\text { 2. Cyclic ingestion } \\
\text { 3. Carbonation } \\
\text { 4. Effortful swallow } \\
\text { 5. Mendelsohn maneuver } \\
\text { 6. Sour bolus }\end{array}$ & $\begin{array}{l}\text { 1. Expiratory muscle strength training } \\
\text { 2. Effortful swallow } \\
\text { 3. Mendelsohn maneuver } \\
\text { 4. Gargling }\end{array}$ \\
\hline
\end{tabular}


Table 1 continued

\begin{tabular}{|c|c|c|c|c|}
\hline Occurring & Sign & $\begin{array}{l}\text { Secondary to physiologic } \\
\text { abnormality of... }\end{array}$ & Possible compensation strategies & Possible exercise approaches \\
\hline $\begin{array}{l}\text { Post- } \\
\text { swallow }\end{array}$ & $\begin{array}{l}\text { Vallecular } \\
\text { residue }\end{array}$ & $\begin{array}{l}\text { Intrinsic epiglottic tissue } \\
\text { changes }\end{array}$ & $\begin{array}{l}\text { 1. Dry swallow } \\
\text { 2. Cyclic ingestion } \\
\text { 3. Carbonation }{ }^{\mathrm{a}} \\
\text { 4. Sour bolus }\end{array}$ & No available exercises \\
\hline $\begin{array}{l}\text { Post- } \\
\text { swallow }\end{array}$ & $\begin{array}{l}\text { Decreased UES } \\
\text { opening }\end{array}$ & $\begin{array}{l}\text { Reduced anterior HLC } \\
\text { movement }\end{array}$ & $\begin{array}{l}\text { 1. Head turn to EITHER SIDE } \\
\text { 2. Mendelsohn maneuver }{ }^{\text {b }}\end{array}$ & $\begin{array}{l}\text { 1. Mendelsohn maneuver } \\
\text { 2. Shaker exercise } \\
\text { 3. Shaker variations }{ }^{\mathrm{a}}\end{array}$ \\
\hline $\begin{array}{l}\text { Post- } \\
\text { swallow }\end{array}$ & $\begin{array}{l}\text { Decreased UES } \\
\text { opening }\end{array}$ & $\begin{array}{l}\text { Intrinsic UES tissue } \\
\text { changes }\end{array}$ & $\begin{array}{l}\text { 1. Head turn to EITHER SIDE } \\
\text { 2. Mendelsohn maneuver }{ }^{\text {b }}\end{array}$ & No available exercises \\
\hline $\begin{array}{l}\text { Post- } \\
\text { swallow }\end{array}$ & $\begin{array}{l}\text { Unilateral } \\
\text { pyriform } \\
\text { sinus residue }\end{array}$ & $\begin{array}{l}\text { Unilateral pharyngeal } \\
\text { hemiparesis }\end{array}$ & 1. Head turn to WEAKER side & No available exercises \\
\hline $\begin{array}{l}\text { Post- } \\
\text { swallow }\end{array}$ & $\begin{array}{l}\text { Bilateral } \\
\text { pyriform } \\
\text { sinus residue }\end{array}$ & $\begin{array}{l}\text { Decreased UES opening } \\
2^{\circ} \text { reduced anterior HLC } \\
\text { movement }\end{array}$ & $\begin{array}{l}\text { 1. Dry swallow } \\
\text { 2. Cyclic ingestion } \\
\text { 3. Head turn to EITHER SIDE } \\
\text { 4. Carbonation } \\
\text { a } \\
\text { 5. Mendelsohn maneuver }{ }^{\mathrm{b}} \\
\text { 6. Sour bolus }{ }^{\mathrm{b}}\end{array}$ & $\begin{array}{l}\text { 1. Mendelsohn maneuver } \\
\text { 2. Shaker exercise } \\
\text { 3. Shaker variations }{ }^{\mathrm{a}}\end{array}$ \\
\hline $\begin{array}{l}\text { Post- } \\
\text { swallow }\end{array}$ & $\begin{array}{l}\text { Bilateral } \\
\text { pyriform } \\
\text { sinus residue }\end{array}$ & $\begin{array}{l}\text { Intrinsic UES tissue } \\
\text { changes }\end{array}$ & $\begin{array}{l}\text { 1. Dry swallow } \\
\text { 2. Cyclic ingestion } \\
\text { 3. Head turn to EITHER SIDE } \\
\text { 4. Carbonation } \\
\text { a } \\
\text { 5. Mendelsohn maneuver }{ }^{\mathrm{b}} \\
\text { 6. Sour bolus }\end{array}$ & No available exercises \\
\hline Pre-swallow & $\begin{array}{l}\text { Airway } \\
\text { invasion }\end{array}$ & Pharyngeal pooling & $\begin{array}{l}\text { 1. 3-s preparation } \\
\text { 2. Chin tuck } \\
\text { 3. Volume regulation } \\
\text { 4. Thickened liquids } \\
\text { 5. Thermal tactile application }{ }^{\mathrm{b}} \\
\text { 6. Sour bolus } \\
\text { 7. Super-supraglottic swallow }\end{array}$ & $\begin{array}{l}\text { Refer to exercise approaches associated } \\
\text { with underlying impairment that is } \\
\text { yielding penetration }\end{array}$ \\
\hline $\begin{array}{l}\text { During } \\
\text { swallow }\end{array}$ & $\begin{array}{l}\text { Airway } \\
\text { invasion }\end{array}$ & $\begin{array}{l}\text { Inadequate epiglottic } \\
\text { deflection }\end{array}$ & $\begin{array}{l}\text { 1. Chin tuck } \\
\text { 2. Effortful swallow }{ }^{\mathrm{b}, \mathrm{d}} \\
\text { 3. Mendelsohn maneuver }\end{array}$ & \\
\hline $\begin{array}{l}\text { During } \\
\text { swallow } \\
\text { Post- } \\
\text { swallow }\end{array}$ & $\begin{array}{l}\text { Airway } \\
\text { invasion }\end{array}$ & Oral residue & $\begin{array}{l}\text { 1. Dry swallow } \\
\text { 2. Cyclic ingestion } \\
\text { 3. Carbonation } \\
\text { a } \\
\text { 4. Sour bolus }\end{array}$ & \\
\hline $\begin{array}{l}\text { Post- } \\
\text { swallow }\end{array}$ & $\begin{array}{l}\text { Airway } \\
\text { invasion }\end{array}$ & Pharyngeal residue & $\begin{array}{l}\text { Refer to compensatory approaches } \\
\text { associated with specific location and } \\
\text { cause of residue }\end{array}$ & \\
\hline $\begin{array}{l}\text { Pre-swallow } \\
\text { During } \\
\text { swallow }\end{array}$ & $\begin{array}{l}\text { Airway } \\
\text { invasion }\end{array}$ & $\begin{array}{l}\text { Reduced laryngeal } \\
\text { valving }\end{array}$ & $\begin{array}{l}\text { 1. Chin tuck } \\
\text { 2. Super-supraglottic swallow }\end{array}$ & No available exercises \\
\hline
\end{tabular}


Table 1 continued

\begin{tabular}{|c|c|c|c|c|}
\hline Occurring & Sign & $\begin{array}{l}\text { Secondary to physiologic } \\
\text { abnormality of... }\end{array}$ & Possible compensation strategies & Possible exercise approaches \\
\hline $\begin{array}{l}\text { Pre-swallow } \\
\text { During } \\
\text { swallow }\end{array}$ & Aspiration & $\begin{array}{l}\text { Reduced true vocal fold } \\
\text { adduction }\end{array}$ & $\begin{array}{l}\text { 1. Head turned to WEAKER SIDE } \\
\text { 2. Supraglottic swallow }\end{array}$ & Laryngeal adduction exercises \\
\hline \multicolumn{5}{|c|}{$\begin{array}{l}\text { Adapted from "Compensatory management of oropharyngeal dysphagia" (pp. 273-5) and "Rehabilitation of oropharyngeal dysphagia" (pp. } \\
\text { 304-7) in Dysphagia Following Stroke by Stephanie K. Daniels and Maggie-Lee Huckabee. Copyright }{ }^{\odot} 2014 \text { Plural Publishing, Inc. All rights } \\
\text { reserved. Used with permission }\end{array}$} \\
\hline \multicolumn{5}{|c|}{$\begin{array}{l}\mathrm{BOT}=\text { base of tongue, } \mathrm{PPW}=\text { posterior pharyngeal wall, } \mathrm{HLC}=\text { hyolaryngeal complex, UES }=\text { upper esophageal sphincter, } 2^{\circ}=\text { secondary } \\
\text { to }\end{array}$} \\
\hline \multicolumn{5}{|c|}{${ }^{a}$ Limited/indirect evidence } \\
\hline \multicolumn{5}{|c|}{${ }^{\mathrm{b}}$ Feasibility questioned } \\
\hline \multicolumn{5}{|c|}{${ }^{\mathrm{c}}$ Pooling to hypopharynx may increase aspiration risk } \\
\hline Ensure no $\mathrm{r}$ & estriction on & movement & & \\
\hline
\end{tabular}

ensure implementation. To support this notion, Rasley et al. [5] identified decreased effectiveness of postures in preventing aspiration for patients with cognitive or language deficits. These findings emphasize the importance of independently evaluating the integrity of each patient's cognitive and language skills prior to recommending compensatory strategies. Clinicians must also validate the effectiveness of each compensatory strategy during an instrumental swallowing examination.

Given shorter LOS in both acute care and rehabilitation settings, active coordination of care is vital to ensure that the patient receives appropriate management for dysphagia and continued assessment to identify improvement in swallowing as well as cognition and language in order to move the patient to a least restrictive compensatory strategy (e.g., chin tuck instead of thickened liquids) as cognition and language improve or to remove the compensatory technique altogether as swallowing improves. If a patient continues to require compensation for safe and efficient swallowing upon discharge to home, it is imperative that the clinician continue to follow the patient and discontinue use of compensation as warranted.

\section{Postural Techniques}

\section{Chin Tuck}

The chin tuck requires patients to tuck their chin toward their neck [6]. It was initially designed to immediately improve swallowing safety by reducing aspiration of thin liquids before onset of the pharyngeal swallow due to a delayed pharyngeal swallow or reduced orolingual control [7]. While the initial assumption supporting the chin tuck was increased vallecular space to contain the pooled liquid [7], research revealed no change in vallecular dimensions [6]. Instead, narrowing of laryngeal vestibule entrance [6] and increased duration of laryngeal vestibule closure [8] have been identified. Importantly, the chin tuck reduces airway invasion when pooling is limited to the valleculae, but can increase the risk of airway invasion if pooling is to the level of the pyriform sinuses [9] as the hypopharynx shortens and narrows during swallowing causing material to overflow into the larynx. This finding along with inconsistent success of the chin tuck in preventing thin liquid aspiration in patients with progressive neurological diseases and stroke [10-12] highlights the importance of testing the effects of chin tuck, or any compensatory strategy, during an instrumental swallowing examination before implementing.

The chin tuck has also been suggested as a compensatory strategy to reduce vallecular residue secondary to reduced BOT retraction to the posterior pharyngeal wall (PPW) [1, 6, 13]. The rationale to support this is the identification of greater approximation of the laryngeal surface of the epiglottis to the PPW [6] which suggests less distance between the BOT and PPW. Variable results in tongue driving force with the chin down posture have been identified in healthy adults [14, 15]; however, to our knowledge, the effects of chin tuck in reducing vallecular residue have not been studied in a patient population.

\section{Head Turn}

The head turn posture requires patients to rotate their head, generally to the weaker side of the pharynx, that is, the specific pyriform sinus in which residue is contained due to pharyngeal hemiparesis $[7,16]$ or to the side in which reduced vocal fold adduction is evident [17]. Head turning results in closure of the hemipharynx at the level of the hyoid with the actual pyriform sinus remaining opened [18]. To identify pharyngeal hemiparesis, clinicians must confirm whether the pyriform sinus residue is unilateral or bilateral. This information is easily obtained with an 
anterior-posterior view during the videofluoroscopic swallowing study (VFSS) or during a videoendoscopic swallowing study (VESS). Reduced vocal fold adduction may also be identified with both studies as the patient phonates "ah." Case studies in individuals with dysphagia following lateral medullary stroke have demonstrated improved bolus clearance with implementation of head turn to the weaker side [19].

Additionally, head turn to either side is suggested to decrease bilateral pyriform sinus residue secondary to reduced upper esophageal sphincter (UES) opening [19]. Decreased UES resting pressure [19, 20] as well as longer duration of UES opening [20] has been identified with head turn during swallowing in healthy adults. Reduced aspiration for thin liquids was identified with use of a head turn posture [5]; however, the percent of improvement based on underlying impairment (pharyngeal hemiparesis, impaired vocal fold closure, and reduced UES opening) was not indicated

\section{Sensory Enhancement}

\section{Temperature}

Altering the temperature of the bolus is one type of change in the sensory element designed to affect swallowing. Change in temperature was theoretically designed to decrease airway invasion occurring before onset of the pharyngeal swallow as well as decrease oral transit time for individuals with reduced oral sensation [4, 17].

The effects of cold temperature on swallowing have been the primary focus of study with investigations generally conducted with young, healthy participants. The majority of research suggests minimal effects of temperature on pharyngeal peristalsis [21], duration of true vocal fold closure [22], and elicitation of a pharyngeal swallow [23]. A recent study identified changes in swallowing reaction times (time from cue to swallow until onset of the pharyngeal swallow) with both cold and carbonated liquids [24]. No significant swallowing effects were identified with a cold bolus in patients with dysphagia following stroke [25]. The overall implications of these studies provide little support for the use of a cold bolus to facilitate swallowing.

\section{Carbonation}

Carbonation is another type of sensory enhancement strategy. The use of carbonation was designed to decrease post swallow residue and reduce airway invasion occurring before onset of the pharyngeal swallow [17]. Findings are variable concerning the effects of carbonation on swallowing in healthy adults with some studies showing improvement on various outcomes [24, 26], and other identifying no changes [27]. Studies in the neurogenic population are more uniform concerning positive effects of carbonated beverages on swallowing with reduced post swallow residue [28, 29], reduced airway invasion [28, 30], and decreased pharyngeal transit time [28] identified. It is important to note that Bülow et al. [28] paired carbonation with a cued swallow, thus it is unclear which variable yielded the change or if the combination of both is required to produce positive effects on swallowing.

\section{Sour Bolus}

Sour bolus is the third sensory enhancement suggested to facilitate swallowing by improving onset of the pharyngeal swallow [31]. Sour has been shown to improve various aspects of swallowing such as increased amplitude [27, 32] and strength of contraction [33] for submental muscles and increased tongue swallowing pressure [34]. A sour bolus can also decrease oral and pharyngeal transit times, improve onset of the pharyngeal swallow and oropharyngeal swallowing efficiency [31], and decrease airway invasion and increase spontaneous dry swallows [35] in patients with neurogenic dysphagia. While sour bolus appears to have the strongest evidence of all the sensory enhancement strategies in improving swallowing, it is currently not a feasible compensatory strategy as no individual would find such an intense sour taste palatable, and currently, a strong sour taste is required to achieve effective results.

\section{Increasing Volitional Control}

\section{3-s Preparation}

The 3-second preparation is a compensatory strategy that increases a patient's volitional control in an attempt to improve swallowing ability [1]. When implementing the 3 s preparation, the patient silently counts to three before onset of oral transfer. This compensatory technique was designed to facilitate and organize execution of oral transfer as well as facilitate onset of the pharyngeal swallow. There is no direct empirical evidence to support the effects of 3-second preparation on swallowing; however, there is indirect evidence which support its rationale. First, verbal cue to swallow has been shown to decrease oral transit time and stage transit duration and facilitate maintenance of the bolus superior to or at the level of the mandibular angle prior to onset of the pharyngeal swallow [36]. Second, it is suggested that self-cue to swallow may facilitate swallowing [37]. 
Viscosity/Volume Manipulation

\section{Thickened Liquids}

Thickening liquids is a method of increasing the material's consistency, which in turn reduces the speed of the bolus [38]. The introduction of thickened liquids was designed to minimize airway invasion before the swallow due to reduced oral lingual control or a delayed pharyngeal swallow [13]. Research demonstrated that honey thick liquid was better than nectar thick liquid (which was better than chin tuck posture) in reducing liquid aspiration during the VFSS in patients with progressive neurogenic dysphagia [11]. It is important to note, however, that one-half of the patients continued to aspirate, regardless of the compensatory strategy utilized, which once again stresses the importance of testing the effects of compensation during the instrumental examination. In a follow-up study, aspiration pneumonia was greater in individuals randomized to receive honey thick liquid to compensate for thin liquid aspiration as compared to those who received nectar thick liquid or implemented a chin tuck posture with thin liquids [39].

While thickening liquids is frequently recommended by clinicians [40], and is easy to implement, even for patients with cognitive deficits if using the pre-mixed variety, patient satisfaction is low [11], thus causing concern for compliance, as well as dehydration, due to limited intake [41]. Depending on a patient's comprehension and cognition, thickened liquids may be the only viable recommendation to ensure safety of liquid intake. Ideally, this is a short-term recommendation as the clinician initiates rehabilitation to address the underlying swallowing impairment to yield removal of any compensatory strategy.

A "free" water protocol has been suggested as a way to reduce dehydration and improve satisfaction when a patient is receiving thickened liquids [42]. Using this type of protocol, the patient has unrestricted access to water; however, this access is removed during mealtime and for 30 min following the meal to allow clearing of residue. Successful compensatory strategies are recommended during water intake. For individuals with cognitive and/or comprehension deficits, free water under supervision is recommended. Aggressive oral hygiene is promoted with the free water protocol. Research on the use of "free" water protocols is limited with contradictory findings [4345]. Some studies reported no adverse events in patients randomized to either the free water group or the thickened liquid only control group [43, 44], whereas another study identified significantly increased risk of respiratory infection in patients randomized to free water [45]. Rather than instituting a single protocol for all patients in a single facility or hospital ward, it seems more intuitive to evaluate the appropriateness of allowing water for patients with thin liquid aspiration on a case-by-case basis.

\section{Volume Regulation}

Volume regulation is a compensatory strategy that reduces the amount of liquid volume presented to a patient during oral feedings. Volume regulation prevents aspiration with large liquid volumes secondary to reduced oral lingual control or a delayed pharyngeal swallow [1]. Currently, there are commercially available cups and straws that regulate volume; however, these products have not been empirically evaluated with regards to patient satisfaction, prevention of aspiration, or maintenance of volume over time. Volume regulation may be ideal for patients who are too cognitively impaired to self-regulate their volume intake. One concern with volume regulation is the decreased amount of thin liquid presented to patients (e.g., volume per swallow limited to 5 or $10 \mathrm{ml}$ ) which could potentially lead to dehydration. Studies using these volume regulating devices are warranted.

\section{Breath-Holding Techniques}

The supraglottic swallow and the super-supraglottic swallow are two voluntary breath-holding compensatory strategies designed to minimize airway invasion by facilitating volitional airway protection [13, 46]. The supraglottic swallow provides airway protection at the level of the true vocal folds, while the super-supraglottic swallow provides airway protection at the level of the laryngeal vestibule. Breath-holding strategies were initially designed for patient's status post head and neck surgery [7, 47, 48]. The use has been broadened to other patient populations demonstrating airway invasion before or during the swallow [13]; however, research has identified increased cardiovascular risk when using either breath-holding techniques for individuals with dysphagia following stroke [49]. Additionally, both techniques also involve multiple steps that must be correctly sequenced, thus good comprehension and memory are important. Endurance is equally critical for an individual to incorporate the strategy throughout the duration of a meal. Hence, careful consideration of appropriate patients with stroke-related dysphagia and consultation with the patient's physician are essential prior to implementation.

\section{Swallowing Exercises}

While compensatory strategies are utilized to provide immediate benefits to ensure safe and efficient swallowing during oral alimentation, the purpose of exercise is to 
eliminate the need for compensation. Thus, they are completed outside of mealtime. Swallowing exercises should be chosen based on the underlying impairment which must be identified in the instrumental swallowing examination (Table 1). Although swallowing exercises should be attempted with all individuals, appropriate patients should present with relatively intact cognition and comprehension or with the ability to imitate the clinician. As discussed later, many swallowing exercises require physical strength and stamina in addition to good comprehension and memory. Thus, many patients will need to gradually increase endurance before the expected number of repetitions for an exercise can be completed. While hospitalized, the clinician can provide direct instructions and supervision for all of the rehabilitation exercises. As rehabilitation may continue to be required upon discharge, it is important to train the patient and/or caregiver on how to complete the exercises independently, particularly as many are performed daily. Performance can be monitored during weekly outpatient sessions, through weekly phone calls, and/or through telerehabilitation. Ideally improvement in swallowing will be measured with an instrumental examination. VESS can easily be used to monitor improvement in signs, i.e., airway invasion, residue, with VFSS used to confirm improvement/resolution of underlying impairment.

\section{Lingual Resistance Exercises}

The principle of lingual resistance is to facilitate swallowing by strengthening tongue muscles. Tongue strengthening exercises can be completed using a tongue depressor [50], the Iowa oral performance instrument (IOPI) [51, 52], or the SwallowSTRONG ${ }^{\circledR}$ device [53•], all of which are portable. The KayPentax Swallow Workstation can also be used in the exercise of the tongue, but it is not portable. With the IOPI and SwallowSTRONG ${ }^{\circledR}$ device, the isometric progressive oropharyngeal (I-PRO) therapy protocol is recommended [53•]. With the I-PRO therapy program, the patient compresses the bulb/sensor between the tongue and hard palate. The baseline maximum pressure at specific targeted locations is initially determined. During the first week of exercise, patients exercise with a goal of $60 \%$ of baseline maximum pressure; this is then increased to $80 \%$ of maximum for the remaining 7 weeks. As strength increases, maximum pressure is recalculated. The I-PRO therapy regimen is completed 3 times a day, 3 days a week for 8 weeks. Following treatment, healthy older adults have demonstrated increased isometric and swallowing pressures and increased muscle size [51]. In a subsequent study of individuals with dysphagia following stroke, 8-weeks of I-PRO therapy using the IOPI resulted in significant increases in isometric and swallowing pressures, tongue hypertrophy, speed of oral transit and quality of life measures, and significant decrease in airway invasion. Reduced pharyngeal wall residue was also significantly reduced, generally with liquid; however, residue in the oral cavity, valleculae, and pyriform sinuses did not significantly change following therapy. While the use of lingual resistance exercises has been suggested to reduce oral and vallecular residue [1], the absence of positive findings thus far and no research, to our knowledge, assessing BOT to PPW pressures, lingual resistance appears most appropriate for improving orolingual control. Further research is warranted to confirm benefit for clearance of residual, typically occurring with thicker consistencies.

\section{Masako Maneuver}

The Masako, or tongue hold, maneuver is designed to reduce vallecular residue by focusing on increasing superior constrictor contraction to compensate for reduced BOT retraction [54]. Hence, it was not designed to increase BOT retraction. Recent research suggests that it also may improve oral lingual strength [55]. The Masako maneuver is performed by placing the tongue between the incisors as the individual swallows saliva. For edentulous patients who cannot maintain the tongue between the gums, the patients can hold their tongue tip with their hand or the clinician may do so with a gloved hand. Unlike other so-called maneuvers, the Masako maneuver is not designed as a compensatory strategy; that is, it should not be used during mealtime. It is critical that only saliva be swallowed using this maneuver as restricting tongue movement will increase pharyngeal residue [56] and may impair bolus propulsion through the pharynx and result in a reduced airway protection [57].

Observation of the Masako maneuver during VFSS in healthy adults revealed increased anterior movement of the PPW [56]. Furthermore, increased BOT to PPW pressure was identified in three patients treated for head and neck cancer and upper pharyngeal residue was reduced [58]. It is important to note that the effects of the Masako maneuver have not been studied using a rehabilitation exercise paradigm in any individuals, particularly those with dysphagia.

\section{Gargling}

Like the Masako maneuver, the effects of gargling have been examined only under fluoroscopy [59]. In a single session study during VFSS, gargling, yawning, tongue pullback, and swallowing were evaluated in patients with dysphagia to determine which movement achieved the greatest posterior tongue movement. Gargling resulted in greater posterior BOT movement. No studies have been 
completed to determine the rehabilitative effects, if any, of gargling on improved BOT retraction and reduced vallecular residue.

\section{Shaker Exercise}

The Shaker exercise increases opening of the UES by strengthening suprahyoid muscles [60]. Thus, this exercise is prescribed for individuals with bilateral pyriform sinus residue and/or post-swallow aspiration due to decreased anterior hyolaryngeal movement resulting in reduced UES opening. The exercise, completed in the supine position, involves two components. The isometric component consists of a 1-min sustained head raise to observe toes. Three trials are completed with a 1-min rest between each sustained head raise. The isokinetic component consists of thirty consecutive repetitions of head raising and lowering without rest between the repetitions. The Shaker exercise is completed three times a day for 6 weeks. Many individuals may be too weak to complete the full duration and repetitions and, therefore, require gradual increase as endurance improves. The 6-week time frame begins once maximum repetitions and sustained duration is achieved. As the Shaker exercise is completed in the supine position, it should be completed prior to a meal or $1 \mathrm{~h}$ following a meal. The same holds true for patients receiving nutrition via tube feeding. Patients receiving tube feeding secondary to chronic dysphagia demonstrated significantly increased UES opening and anterior laryngeal movement following completion of the Shaker exercise regime [61]. In addition, all patients resumed oral intake without diet restrictions. Contraindications for the Shaker exercise are tracheostomy tube placement and limitations in neck mobility. It is not contraindicated for patients with cardiovascular disease or stroke.

\section{Variations on the Shaker Exercise}

Two new exercises, jaw opening [62] and chin tuck against resistance (CTAR) [63], have been introduced, which are similar to the Shaker exercise in that they are designed to facilitate opening of the UES by targeting suprahyoid contraction. It is suggested that they may be easier than the Shaker exercise for clients to complete. For the jaw opening exercise, individuals complete four repetitions of holding the jaw in the maximally opened position for $10 \mathrm{~s}$, with $10 \mathrm{~s}$ of rest in between repetitions [62]. Two sets of five repetitions are completed daily for 4 weeks. After 4 weeks, individuals with dysphagia characterized by reduced UES opening demonstrated significant increases in superior hyoid movement and UES opening width. Anterior hyoid movement, however, did not significantly increase, and pharyngeal residue did not significantly decrease. There was no discussion of the mechanism that could have resulted in the increased UES opening without parallel increase in anterior hyoid movement.

CTAR involves two components: compressing a ball between the chin and manubrium of the sternum for $10 \mathrm{~s}$ and 10 consecutive repetitions of ball compression [63]. Five minutes of rest separates the two components. Individuals are instructed to keep their mouths closed, shoulders stationary, and use one hand to keep the ball in position. Suprahyoid muscle activation was greater for both components of CTAR following a single trial as compared to a single trial of both components of the Shaker exercise in a group of healthy young adults. Before widespread implementation of these exercises is recommended, more extensive research in patient populations is warranted.

\section{Expiratory Muscle Strength Training}

Expiratory muscle strength training (EMST) was originally designed to increase respiratory function; however, its effects on swallowing biomechanics have led to plausible application as a rehabilitative strategy for dysphagia [64]. In EMST, individuals blow into a one-way spring-loaded device calibrated to a specific percentage of maximum expiratory pressure until the valve opens with sufficient effort $[65,66,67 \cdot \bullet]$. The treatment duration is 4 weeks with 5 sets completed 5 days per week.

The effects of EMST have been studied in healthy young and older adults and individuals with progressive neurological diseases such as Parkinson disease and multiple sclerosis. Findings have revealed improved hyoid elevation [67••, 68], reduced airway invasion [67••], and increased cough force $[66,67 \bullet \bullet, 69,70]$. Further, findings suggest the need for maintenance programs to support positive rehabilitative gains $[71 \bullet \cdot]$.

The effects of EMST may be similar to the Valsalva maneuver as it involves a build-up of intraoral and intrathoracic pressure [72]. Completion of breath-holding compensatory strategies (i.e., supraglottic swallow and super-supraglottic swallow) which involve a Valsalva maneuver has been shown to have negative cardiovascular effects in individuals with stroke [49]. Given these potential problems, the effects of EMST and the Valsalva maneuver on blood pressure, heart rate, and oxygen saturation levels were evaluated in healthy adults [72]. No significant changes in measures were observed suggesting that the shorter duration of pressure generation during EMST, about $1.25 \mathrm{~s}$, does not induce negative cardiovascular changes. In addition, no negative effects were observed after the 5-second-long Valsalva maneuver. Replication of this study is warranted in individuals with stroke to confirm safety of EMST with this patient population. 
Treatments with Characteristics of Both Compensation and Exercise

Thermal Tactile Application

Thermal tactile application (TTA) is a sensory enhancement strategy that can be considered both to have both short-term and long-term effects. It is designed to heighten sensory input thereby facilitating onset of the pharyngeal swallow, thus it appropriates to use for individuals with a delayed pharyngeal swallow and pre-swallow airway invasion resulting from the delay [7]. TTA consists of brisk vertical rubbing a chilled 00 laryngeal mirror or ice stick along the anterior faucial arches. Five strokes are completed along each arch and followed by swallowing a small amount of liquid or saliva. Five to 10-min sessions completed 3-4 times a day are recommended [13].

The immediate effects of TTA in improving the onset of the pharyngeal swallow have been identified in individuals with dysphagia secondary to stroke [73, 74], with continued improved elicitation of the swallow maintained for 2-3 subsequent swallows. Before recommending TTA as a compensatory strategy, the clinician must consider the feasibility of completing TTA after every 2-3 liquid swallows during mealtime. For many patients and families, this may not be a viable recommendation.

Like many of our rehabilitative approaches for dysphagia, findings for TTA are not robust. Reduced delay in onset of the pharyngeal swallow has been identified in a small subset of stroke patients; however, there was no change in airway invasion [75].

\section{Effortful Swallow}

The effortful swallow was designed as a compensatory strategy to improve BOT retraction and thereby decrease vallecular residue $[13,76]$, but when used outside of mealtime, it can be completed repetitively as a strengthening exercise. Instructions have varied widely in the literature and include: "as you swallow, squeeze hard with all of your muscles" [13, p. 221], "swallow hard" [77, p. 1662], "swallow very hard while squeezing the tongue in an upward-backward motion toward the soft palate" [78, p. 69]. Research in healthy adults suggests that emphasizing the tongue to palate contact, "as you swallow, push really hard with your tongue" yields increased orolingual and pharyngeal pressures [79, p. 1068].

Research on the effects of effortful swallow has been conducted primarily in healthy young and older adults and has identified increased pharyngeal and lingual pressures as well increased duration of UES opening and maximum anterior movement [e.g., 77, 79, 80]. Negative effects of the effort swallow have been reported and include restriction of laryngeal excursion [78] and nasal backflow [81]. To our knowledge, no study has investigated the effects of effortful swallow used as a single rehabilitation exercise.

\section{Mendelsohn Maneuver}

The Mendelsohn maneuver requires the patient to initiate the swallow and at the peak of hyolaryngeal excursion and maintains suprahyoid contraction before relaxing and completing the swallow [82, 83]. Thus, it is designed for reduced UES opening and pyriform sinus residue. As with the effortful swallow, the Mendelsohn maneuver was initially designed as a compensatory technique but is now also considered a strengthening exercise when performed outside of mealtime. Surface electromyography (sEMG) can be used with both the effortful swallow and the Mendelsohn maneuver to provide visual feedback and mastery of the technique. When recommending either the Mendelsohn maneuver or effortful swallow as a compensatory strategy, the clinician must consider the endurance of the patient and if the compensation could realistically be maintained over the duration of the meal or would it lead to fatigue and possibly early meal termination.

The effects of the Mendelsohn maneuver as a rehabilitation exercise have been investigated in patients with dysphagia following stroke [84••, 85•]. Using sEMG biofeedback, patients were instructed to swallow "long and strong" 30-40 times per session, twice a day for 2 weeks. Results revealed increased duration of anterior and superior hyolaryngeal movement and UES opening [84.•] as well as decreased airway invasion and pyriform sinus residual $[85 \bullet$.

\section{Rehabilitation Adjuncts}

Neuromuscular electrical stimulation (NMES) is a therapeutic modality for dysphagia that has entered clinical practice before research has fully concluded clinical benefit and contraindications. NMES is designed to augment the motor pattern by administration of pulsed electrical current to the target. VitalStim ${ }^{\mathrm{TM}}$ has gained popularity as a transcutaneous NMES to improve hyolaryngeal movement, although research has reported substantially limited to no benefits on swallowing ability [e.g., 86, 87]. Additionally, negative effects of VitalSim ${ }^{\mathrm{TM}}$ such as significant hyoid depression have been identified [88, 89]. In studies in which improvement in swallowing has been identified [90], VitalStim $^{\text {TM }}$ was paired with effortful swallow for $1 \mathrm{~h}$ sessions completed 5 days per week for 3 weeks. Thus, it is unknown if it was the VitalStim ${ }^{\mathrm{TM}}$, the effortful swallow, the mass practice, or a combination of these that lead to positive results. As with all rehabilitative treatments, 
VitalStim $^{\mathrm{TM}}$ is not designed to ameliorate all underlying swallowing impairments; it can be used as a resistance exercise only for individuals with reduced hyolaryngeal elevation [89, 91] which must be identified with a VFSS. Once the appropriate underlying impairment is confirmed, the clinician should test effects of VitalSim ${ }^{\mathrm{TM}}$ in VFSS to determine if the patient can overcome hyolaryngeal depression. If the patient cannot overcome the depression, VitalStim $^{\mathrm{TM}}$ should not be recommended.

\section{Conclusions}

Many treatment strategies for oropharyngeal dysphagia following stroke are available to clinicians. As is evident, some compensatory and exercise approaches have more evidence compared to others. Given limited LOS durations for both acute care and rehabilitation hospitalizations following stroke, it is critical that dysphagia clinicians carefully weigh the external evidence (research literature) and the internal evidence (patient/family factors) to determine the optimal treatment plan for each individual patient.

\section{Compliance with Ethics Guidelines}

Conflict of Interest DN Johnson, HJ Herring, and SK Daniels all declare no conflicts of interest.

Human and Animal Rights and Informed Consent This article does not contain any studies with human or animal subjects performed by any of the authors.

\section{References}

Recent publications of particular interest have been highlighted as:

- Of importance

-• Of major importance

1. Daniels SK, Huckabee ML. Dysphagia following stroke. 2nd ed. San Diego: Plural; 2014.

2. Hall MJ, Levant S, DeFrances CJ. (2012). Hospitalization for stroke in U.S. hospitals 1989-2009. http://www.cdc.gov/nchs/ data/databriefs/db95.htm Accessed 30 June 2014.

3. Concentric Medical. Hospital inpatient 2012 Medicare payment and policy update. http://www.concentric-medical.com/resources/ APM0311_F_Brochure,\%20Hospital\%20Inpatient\%202012\%20 Medicare\%20Payment\%20and\%20Policy\%20Update.pdf. Accessed 30 June 2014.

4. Butler SG, Pelletier CA, Steele CM. Compensatory strategies and techniques. In: Shaker R, Easterling C, Belafsky PC, Postma GN, editors. Manual of diagnostic and therapeutic techniques for disorders of deglutition. New York: Springer; 2013. p. 299-316.

5. Rasley A, Logemann JA, Kahrilas PJ, Rademaker AW, Pauloski BR, Dodds WJ. Prevention of barium aspiration during videofluoroscopic swallowing studies: value of change in posture. AJR Am J Roentgenol. 1993;160:1005-9.

6. Welch MW, Logemann JA, Rademaker AW, Kahrilas PJ. Changes in pharyngeal dimensions effected by chin tuck. Arch Phys Med Rehabil. 1993;74:178-81.

7. Logemann JA. Evaluation and treatment of swallowing disorders. 1st ed. San Diego: College-Hill; 1983.

8. Macrae P, Anderson C, Humbert I. Mechanisms of airway protection during chin-down swallowing. J Speech Lang Hear Res. 2014. doi:10.1044/2014_JSLHR-S-13-0188.

9. Shanahan TK, Logemann JA, Rademaker AW, Pauloski BR, Kahrilas PJ. Chin-down posture effect on aspiration in dysphagic patients. Arch Phys Med Rehabil. 1993;74:736-9.

10. Fraser S, Steele CM. The effect of chin down position on penetration-aspiration in adults with dysphagia. Can. J Speech Lang Pathol Aud. 2012;36:142-8.

11. Logemann JA, Gensler G, Robbins J, Lindblad A, Brandt D, Hind $\mathrm{JA}$, et al. A randomized study of three interventions for aspiration of thin liquids in patients with dementia and Parkinson's disease. J Speech Lang Hear Res. 2008;51:173-83.

12. Nagaya M, Kachi T, Yamada T, Sumi Y. Videofluorographic observations on swallowing in patients with dysphagia due to neurodegenerative diseases. Nagoya J Med Sci. 2004;67:17-23.

13. Logemann JA. Evaluation and treatment of swallowing disorders. 2nd ed. Austin: Pro-Ed; 1998.

14. Hori K, Tamine K, Barbezat C, Maeda Y, Yamori M, Muller F, et al. Influence of chin-down posture on tongue pressure during dry swallow and bolus swallows in healthy subjects. Dysphagia. 2011;26:238-45.

15. McCulloch TM, Hoffman MR, Ciucci MR. High resolution manometry of pharyngeal swallow pressure events associated with head turn and chin tuck. Ann Otol Rhinol Laryngol. 2010;119:369-76.

16. Kirchner JA, Scatliff JH, Dey FL, Shedd DP. The pharynx after laryngectomy. Changes in its structure and function. Laryngoscope. 1963;73:18-33.

17. Logemann JA. Manual for videofluoroscopic study of swallowing. 2nd ed. Austin: Pro-Ed; 1993.

18. Tsukamoto Y. CT study of closure of the hemipharynx with head rotation in a case of lateral medullary syndrome. Dysphagia. 2000;2000(15):17-8.

19. Logemann JA, Kahrilas PJ, Kobara M, Vakil NB. The benefit of head rotation on pharyngoesophageal dysphagia. Arch Phys Med Rehabil. 1989;70:767-71.

20. Ohmae Y, Ogura M, Taraho T, Kitahara S, Inouye T. Effects of head rotation on pharyngeal function during normal swallow. Ann Otol Rhinol Laryngol. 1998;107:344-8.

21. Shaker R, Ren J, Podvrsan B, Dodds WJ, Hogan WJ, Kern M, et al. Effect of aging and bolus variables on pharyngeal and upper esophageal sphincter motor function. Am J Physiol. 1993;264:G427-32.

22. Ren J, Shaker R, Zamir Z, Dodds WJ, Hogan WJ, Hoffman RG. Effects of age and bolus variables on the coordination of the glottis and upper esophageal sphincter during swallowing. Am J Gastroenterol. 1993;88:665-9.

23. Shaker R, Ren J, Zamir Z, Sarna A, Liu J, Sui Z. Effect of aging, position, and temperature on the threshold volume triggering pharyngeal swallows. Gastroenterology. 1994;107:396-402.

24. Michou E, Mastan A, Ahmed S, Mistry S, Hamdy S. Examining the role of carbonation and temperature on water swallowing performance: a swallowing reaction-time study. Chem Senses. 2012;37:799-807.

25. Bisch EM, Logemann JA, Rademaker AW, Kahrilas PJ, Lazarus CL. Pharyngeal effects of bolus volume, viscosity, and temperature, in patients with dysphagia resulting from neurologic impairment and in normal subjects. J Speech Hear Res. 1994;37:1041-60. 
26. Krival K, Bates C. Effects of club soda and ginger brew on linguapalatal pressures in healthy swallowing. Dysphagia. 2012;27:228-39.

27. Ding R, Logemann JA, Larson CR, Rademaker AW. The effects of taste and consistency on swallow physiology in younger and older healthy individuals: a surface electromyographic study. J Speech Lang Hear Res. 2003;46:977-89.

28. Bülow M, Olsson R, Ekberg O. Videographic analysis of how carbonated thin liquids and thickened liquids affect the physiology of swallowing in subjects with aspiration on thin liquids. Acta Radiol. 2003;44:366-72.

29. Jennings KS, Siroky D, Jackson CG. Swallowing problems after excision of tumors of the skull base: diagnosis and management in 12 patients. Dysphagia. 1992;7:40-4.

30. Sdravou K, Walshe M. Effects of carbonated liquids on oropharyngeal swallowing measures in people with neurogenic dysphagia. Dysphagia. 2012;27:240-50.

31. Logemann JA, Pauloski BR, Colangelo L, Lazarus C, Fujiu M, Kahrilas PJ. Effects of a sour bolus on oropharyngeal swallowing measures in patients with neurogenic dysphagia. J Speech Hear Res. 1995;38:556-63.

32. Leow LP, Huckabee ML, Sharma S, Tooley TP. The influence of taste on swallowing apnea, oral preparation time, and duration and amplitude of submental muscle contraction. Chem Senses. 2007;32:119-28.

33. Palmer PM, McCulloch TM, Jaffe D, Neel AT. Effects of a sour bolus on the intramuscular electromyographic (EMG) activity of muscles in the submental region. Dysphagia. 2005;20:210-7.

34. Pelletier CA, Dhanaraj GE. The effect of taste and palpability on lingual swallowing pressure. Dysphagia. 2006;21:121-8.

35. Pelletier CA, Lawless HT. Effect of citric acid-sucrose mixtures on swallowing in neurogenic oropharyngeal dysphagia. Dysphagia. 2003;18:231-41.

36. Daniels SK, Schroeder MF, DeGeorge PC, Corey DM, Rosenbek JC. Effects of verbal cue on bolus flow during swallowing. Am J Speech Lang Pathol. 2007;16:140-7.

37. Ludlow CL, Humbert I, Poletto CJ, Saxon KG, Kearney PR, Crujido L. The use of coordination training for the onset of intramuscular stimulation in dysphagia. Proceedings of the International Functional Electrical Stimulation Society. 2005.

38. Dantas RO, Kern MK, Massey BT, Dodds WJ, Kahrilas PJ, Brasseur JG, et al. Effect of swallowed bolus variables on oral and pharyngeal phases of swallowing. Am J Physiol. 1990;258:G675-81.

39. Robbins J, Gensler G, Hind J, Logemann JA, Lindblad AS, Brandt D. Comparison of 2 interventions for liquid aspiration on pneumonia incidence: a randomized trial. Ann Intern Med. 2008;148:509-18.

40. Garcia JM, Chambers ET, Molander M. Thickened liquids: practice patterns of speech-language pathologists. Am J Speech Lang Pathol. 2005;14:4-13.

41. Colodny N. Dysphagic independent feeders' justifications for non-compliance with recommendations by a speech-language pathologist. Am J Speech Lang Pathol. 2005;14:61-70.

42. Panther K. The Frazier free water protocol. Perspect Swal Swal Dis. 2005;14:4-9.

43. Carlaw C, Finlayson H, Beggs K, Visser T, Marcoux C, Coney D, et al. Outcomes of a pilot water protocol project in a rehabilitation setting. Dysphagia. 2012;27:297-306.

44. Garon BR, Engle M, Ormiston C. A randomized control study to determine the effects of unlimited oral intake of water in patients with identified aspiration. J Neurol Rehabil. 1997;11:139-48.

45. Karagiannis MJP, Chivers L, Karagiannis TC. Effects of oral intake of water in patients with oropharyngeal dysphagia. BMC Geriatr. 2011;11:9. doi:10.1186/1471-2318-11-9.
46. Ohmae Y, Logemann JA, Kaiser P, Hanson DG, Kahrilas PJ. Effects of two breath-holding maneuvers on oropharyngeal swallow. Ann Otol Rhinol Laryngol. 1996;105:123-31.

47. Martin BJ, Logemann JA, Shaker R, Dodds WJ. Normal laryngeal valving patterns during three breath-holding maneuvers: a pilot investigation. Dysphagia. 1993;8:11-20.

48. Staple TW, Ogura JH. Cineradiography of the swallowing mechanism following supraglottic subtotal laryngectomy. Radiology. 1966;87:226-30.

49. Chaudhuri G, Hildner CD, Brady S, Hutchins B, Aliga N, Abadilla E. Cardiovascular effects of the supraglottic and supersupraglottic swallowing maneuvers in stroke patients with dysphagia. Dysphagia. 2002;17:19-23.

50. Lazarus C, Logemann JA, Huang CF, Rademaker AW. Effects of two types of tongue strengthening exercises in young normals. Folia Phoniatr Logop. 2003;55:199-205.

51. Robbins J, Gangnon RE, Theis SM, Kays SA, Hewitt AL, Hind JA. The effects of lingual exercise on swallowing in older adults. J Am Geriatr Soc. 2005;53:1483-9.

52. Robbins J, Kays SA, Gangnon RE, Hind JA, Hewitt AL, Gentry LR, et al. The effects of lingual exercise in stroke patients with dysphagia. Arch Phys Med Rehabil. 2007;88:150-8.

53. - Hind JA, Robbins J. Oropharyngeal strengthening and rehabilitation of deglutitive disorders. In: Shaker R, Easterling C, Belafsky PC, Postma GN, editors. Manual of diagnostic and therapeutic techniques for disorders of deglutition. New York: Springer; 2013. A thorough overview of literature concerning orolingual resistance exercises is provided.

54. Fujiu M, Logemann JA, Pauloski BR. Increased post-operative posterior pharyngeal wall movement in patients with anterior oral cancer: preliminary findings and possible implications for treatment. Am J Speech Lang Pathol. 1995;5:24-30.

55. Fujiu-Kurachi M, Fujiwara S, Tamine K, Kondo J, Minagi Y, Maeda $\mathrm{Y}$, et al. Tongue pressure generation during tongue-hold swallows in young healthy adults measured with different tongue positions. Dysphagia. 2014;29:17-24.

56. Fujiu M, Logemann JA. Effect of a tongue-holding maneuver on posterior pharyngeal wall movement during deglutition. Am J Speech Lang Pathol. 1996;5:23-30.

57. Doeltgen SH, Witte U, Gumbley F, Huckabee ML. Evaluation of manometric measures during tongue hold swallows. Am J Speech Lang Pathol. 2009;18:65-73.

58. Lazarus C, Logemann JA, Song CW, Rademaker AW, Kahrilas PJ. Effects of voluntary maneuvers on tongue base function for swallowing. Folia Phoniatr Logop. 2002;54:171-6.

59. Veis MA, Logemann JA, Colangello MS. Effects of three techniques on maximum posterior movement of the tongue base. Dysphagia. 2000;15:142-5.

60. Shaker R, Kern M, Bardan E, Taylor A, Stewart ET, Hoffmann RG, et al. Augmentation of deglutitive upper esophageal sphincter opening in the elderly by exercise. Am J Physoil. 1997;272:G1518-22.

61. Shaker R, Easterling C, Kern M, Nitschke T, Massey B, Daniels $\mathrm{S}$, et al. Rehabilitation of swallowing by exercise in tube-fed patients with pharyngeal dysphagia secondary to abnormal UES opening. Gastroenterology. 2002;122:1314-21.

62. Wada S, Tohara H, Iida T, Inoue M, Sato M, Ueda K. Jawopening exercise for insufficient opening of upper esophageal sphincter. Arch Phys Med Rehabil. 2012;93:1995-9.

63. Yoon WL, Khoo JKP, Liow SJR. Chin tuck against resistance (CTAR): new method for enhancing suprahyoid muscle activity using a Shaker-type exercise. Dysphagia. 2014;29:243-8.

64. Kim J, Sapienza CM. Implications of expiratory muscle strength training for rehabilitation of the elderly: tutorial. J Rehabil Res Dev. 2005;42:211-24. 
65. Saleem AF, Sapienza CM, Okun MS. Respiratory muscle strength training: treatment and response duration in a patient with early idiopathic Parkinson's disease. NeuroRehabilitation. 2005;20:323-33.

66. Pitts T, Bolser D, Rosenbek J, Troche M, Okun MS, Sapienza C. Impact of expiratory muscle strength training on voluntary cough and swallow function in Parkinson disease. Chest. 2009;135: 1301-8.

67. •• Troche MS, Okun MS, Rosenbek JC, Musson N, Fernandez $\mathrm{NH}$, Rodriguez R et al. Aspiration and swallowing in Parkinson disease and rehabilitation with EMST: a randomized trial. Neurology. 2010;75:1912-19. This is well designed study using a randomized, sham-controlled design to investigate the effects of EMST. Results revealed improved swallowing safety and hyolaryngeal movement in the group receiving EMST.

68. Wheeler-Hegland KM, Rosenbek JC, Sapienza CM. Submental sEMG and hyoid movement during Mendelsohn maneuver, effortful swallow, and expiratory muscle strength training. J Speech Lang Hear Res. 2008;51:1072-87.

69. Chiara T, Martin AD, Davenport PW, Bolser DC. Expiratory muscle strength training in persons with multiple sclerosis having mild to moderate disability: effect on maximal expiratory pressure, pulmonary function, and maximal voluntary cough. Arch Phys Med Rehabil. 2006;87:468-73.

70. Kim J, Davenport P, Sapienza C. Effect of expiratory muscle strength training on elderly cough function. Effect of expiratory muscle strength training on elderly cough function. Arch Gerontol Geriatr. 2009;48:361-6.

71. • Troche MS, Rosenbek JC, Okun MS, Sapienza CM. Detraining outcomes with expiratory muscle strength training in Parkinson disease. J Rehabil Res Dev. 2014;51:305-10. The first study to investigate detraining effects following dysphagia rehabilitation. Although a significant decline in swallowing safety was not observed when treatment was stopped, individuals with more severe dysphagia at the beginning of treatment demonstrated a greater detraining effect (i.e.., return to pretreatment swallowing function) compared to individuals with mild dysphagia.

72. Laciuga H, Davenport P, Sapienza CM. The acute effects of a single session of expiratory muscle strength training on blood pressure, heart rate, and oxygen saturation in healthy adults. Front Physiol. 2012;3. doi:10.3389/fphys.2012.00048.

73. Lazzara G, Lazarus C, Logemann JA. Impact of thermal stimulation on the triggering of the swallowing reflex. Dysphagia. 1986;1:73-7.

74. Rosenbek JC, Roecker EB, Wood JL, Robbins J. Thermal application reduces the duration of stage transition in dysphagia after stroke. Dysphagia. 1996;11:225-33.

75. Rosenbek JC, Robbins J, Fishback B, Levine RL. Effects of thermal application on dysphagia after stroke. J Speech Lang Hear Res. 1991;34:1257-68.

76. Pouderoux P, Kahrilas PJ. Deglutitive tongue force modulation by volition, volume, and viscosity in humans. Gastroenterology. 1995;108:1418-26.

77. Hind JA, Nicosia MA, Roecker EB, Carnes ML, Robbins J. Comparison of effortful and noneffortful swallows in healthy middle-aged and older adults. Arch Phys Med Rehabil. 2001;82:1661-5.
78. Bülow M, Olsson R, Ekberg O. Videomanometric analysis supraglottic swallow, effortful swallow, and chin tuck in healthy volunteers. Dysphagia. 1999;14:67-72.

79. Huckabee ML, Steele CM. An analysis of lingual contribution to submental surface electromyographic measures and pharyngeal pressures during effortful swallow. Arch Phys Med Rehabil. 2006;87:1067-72.

80. Huckabee ML, Butler SG, Barclay M, Jit S. Submental surface electromyographic measurement and pharyngeal pressures during normal and effortful swallow. Arch Phys Med Rehabil. 2005;86:2144-9.

81. Garcia JM, Hake M, Lazarus C. Unexpected consequence of effortful swallowing: case study report. J Med Speech Lang Pathol. 2004;12:59-66.

82. Logemann JA, Kahrilas PJ. Relearning to swallow after strokeapplication of maneuvers and indirect biofeedback: a case study. Neurology. 1990;40:1136-8.

83. Kahrilas PJ, Logemann JA, Krugler C, Flanagan E. Volitional augmentation of upper esophageal sphincter. Am J Physiol. 1991;260:G450-6.

84. •• McCullough GH, Kamarunas E, Mann GC, Schmidley JW, Robbins JA, Crary MA. Effects of Mendelsohn maneuver on measures of swallowing duration post stroke. Top Stroke Rehabil. 2012:19:234-43. This is currently the only study to investigate the effects of the Mendelsohn maneuver when used in isolation as a rehabilitation exercise. A randomized control trial cross-over design was employed. Significant increases in the duration of anterior and superior movement was identified.

85. - McCullough GH, Kim Y. Effects of Mendelsohn maneuver on extent of hyoid movement and UES opening post-stroke. Dysphagia. 2013;28:511-19. This is a companion article to the one above with further data analysis. Significant correlations were identified between increase in structural movement and improvement in bolus flow.

86. Bülow M, Speyer R, Baijens L, Woisard V, Ekberg O. Neuromuscular electrical stimulation (NMES) in stroke patients with oral and pharyngeal dysphagia. Dysphagia. 2008;23:203-9.

87. Kiger M, Brown CS, Watkins L. Dysphagia management: an analysis of patient outcomes using VitalStim therapy compared to traditional swallow therapy. Dysphagia. 2006;21:243-53.

88. Humbert IA, Poletto CJ, Saxon KG, Kearney PR, Crujido L, Wright-Harp W, et al. The effect of surface electrical stimulation on hyolaryngeal movement in normal individuals at rest and during swallowing. J Appl Physiol. 2006;101:1657-63.

89. Ludlow CL, Humbert I, Saxon K, Poletto C, Sonies B, Crujido L. Effects of surface electrical stimulation both at rest and during swallowing in chronic pharyngeal dysphagia. Dysphagia. 2007;22:1-10.

90. Carnaby-Mann G, Crary MA. Adjunctive neuromuscular electrical stimulation for treatment-refractory dysphagia. Ann Otol Rhinol Laryngol. 2008;117:564-71.

91. Ludlow CL. Electrical neuromuscular stimulation in dysphagia: current status. Cur Opin Otolaryngol Head Neck Surg. 2010;18:159-64. 